\title{
HUBUNGAN GANGGUAN FUNGSI FISIK DAN DUKUNGAN KELUARGA DENGAN HARGA DIRI LANSIA DI PUSKESMAS PUTRI AYU KOTA JAMBI TAHUN 2019
}

\author{
Firza Fachrunnisa $^{1)}$, Daryanto ${ }^{2)}$, Vevi Suryenti Putri ${ }^{3)}$ \\ 1,2,3 Program Studi Ilmu Keperawatan STIKes Baiturrahim, Jambi \\ Email : firzafachunnisa97@gmail.com
}

\begin{abstract}
Health problems often experienced by the elderly are one of the psychological problems of self-esteem. Self-esteem in the elderly that is not treated will cause low self-esteem problems, factors that affect self-esteem are impaired physical function and low family support. Problems that are often experienced by the elderly are impaired physical function and lack of family support. This study aimed to determine the correlation of physical function impairment and family support with elderly self-esteem at the public health center Putri Ayu Jambi city year 2019. This is a quantitative research by using cross sectional design. Populations were all elderly aged 60-70 who visited at the public health center Putri Ayu Jambi city year 2018 as many as 5655 people. Samples were 95 respondents, it used accidental sampling technique. This study was conducted from May $16^{\text {th }}-29^{\text {th }}$ 2019. The collecting of data used questionnaire. It analyzed as univariate and bivariate by using chi-square test. The findings indicated that as many as $65.3 \%$ have good family support for the elderly, as many as $67.4 \%$ elderly experience mild physical impairment and as many as $38.9 \%$ the elderly have low self-esteem. On the statistical test indicated that there is significant correlation between physical function impairment ( $p$ value 0.000) and family support (p-value 0.007) with elderly self-esteem at the public health center Putri Ayu Jambi city year 2019. It is expected to health personnel at the public health center to increase counseling about elderly health and self-esteem and also increase counseling to elderly families about family support needed by the elderly, especially about physical changes for the elderly, praise for the elderly, elderly needs and health conditions of the elderly.
\end{abstract}

Keywords : Elderly, family support, physical function Impairment

\begin{abstract}
ABSTRAK
Masalah kesehatan yang sering dialami oleh lansia yaitu masalah psikologis salah satunya harga diri. Harga diri pada lansia yang tidak ditangani akan menimbulkan masalah harga diri rendah, faktor yang mempengaruhi harga diri yaitu gangguan fungsi fisik dan dukungan keluarga yang rendah. Masalah yang sering dialami lansia adalah gangguan fungsi fisik dan kurangnya dukungan keluarga. Tujuan penelitian ini adalah untuk mengetahui hubungan gangguan fungsi fisik dan dukungan keluarga dengan harga diri lansia di Puskesmas Putri Ayu Kota Jambi tahun 2019. Penelitian merupakan penelitian kuantitatif dengan desain cross sectional. Populasi penelitian ini yaitu seluruh lansia usia 60-70 tahun yang berkunjung di Puskesmas Putri Ayu tahun 2018 sebanyak 5655 orang. Sampel sebanyak 95 responden menggunakan teknik accidental sampling. Penelitian ini dilakukan dari tanggal 16 - 29 Mei 2019. Data diambil menggunakan kuesioner. Peneliti menggunakan analisa univariat dan bivariat dengan uji chi-square. Hasil penelitian menunjukkan bahwa sebanyak 65,3\% dukungan keluarga pada lansia baik, sebanyak $67,4 \%$ lansia mengalami gangguan fungsi fisik ringan dan sebanyak 38,9\% lansia mempunyai harga diri rendah. Hasil uji statistik menunjukkan ada hubungan yang bermakna antara gangguan fungsi fisik $(p$-value 0,000$)$ dan dukungan keluarga $(p$-value
\end{abstract}


0,007) dengan harga diri lansia di Puskesmas Putri Ayu Jambi tahun 2019. Diharapkan agar petugas kesehatan di Puskesmas meningkatkan penyuluhan tentang kesehatan lansia dan harga diri lansia dan juga meningkatkan penyuluhan kepada keluarga lansia tentang dukungan keluarga yang di butuhkan oleh lansia terutama tentang perubahan-perubahan fisik bagi lansia, pujian untuk lansia, kebutuhan lansia dan kondisi kesehatan lansia.

Kata Kunci : Dukungan keluarga, gangguan fungsi fisik, lansia

\section{PENDAHULUAN}

Jumlah lansia diperkirakan lebih dari 629 juta jiwa (satu dari 10 orang berusia lebih dari 60 tahun), dan pada tahun 2025 di seluruh dunia, lanjut usia akan mencapai 1,2 miliyar. Secara demografis pada tahun 2005-2010 jumlah lansia akan sama dengan jumlah balita, yaitu sekitar 19,3 juta jiwa $( \pm 9 \%)$ dari jumlah penduduk. Bahkan pada tahun 2010-2025 Indonesia akan menduduki peringkat negara dengan struktur dan jumlah penduduk lansia, India dan Amerika Serikat, dengan umur harapan hidup di atas 70 tahun (Nugroho, 2014:2).

Hasil proyeksi penduduk 2010-2035, Indonesia akan memasuki periode lansia (ageing), dimana $10 \%$ penduduk akan berusia 60 tahun ke atas, di tahun 2020. Sebaran penduduk lansia menurut provinsi, dimana provinsi dengan persentase lansia tertinggi adalah DI Yogyakarta $(13,4 \%)$ dan terendah adalah Papua $(2,8 \%)$. Sedangkan di Jambi sebanyak 6,5\% (Kemenkes RI, 2016:2). Jumlah penduduk Provinsi Jambi tahun 2015 sebanyak 3.402.052 jiwa yang terdiri dari lakilaki sebanyak 1.736 .049 orang dan perempuan sebanyak 1.666 .003 orang (Dinkes Provinsi Jambi, 2016). Data yang didapatkan di Dinas Kesehatan Kota Jambi pada tahun 2018 meperlihatkan bahwa Puskesmas Putri Ayu Kota Jambi merupakan salah satu puskesmas dari
20 Puskesmas yang memiliki jumlah lansia terbanyak yaitu 5655 orang. Jumlah jumlah kunjungan lansia bulan Januari-Maret 2019 yaitu sebanyak 2.205 orang.

Lansia suatu proses menghilangnya secara perlahanlahan kemampuan jaringan untuk memperbaiki diri dan mempertahankan struktur dan fungsi normalnya sehingga tidak dapat bertahan terhadapa jejas (termasuk infeksi) dan memperbaiki kerusakana yang diderita (Direja, 2011 : 101). Masalah kesehatan yang paling sering dialami oleh lansia yaitu masalah psikologis diantaranya adalah depresi (Pieter \& Lubis, 2017:92). Depresi pada lansia dapat dipengaruhi oleh berbagai faktor salah satunya adalah harga diri. Harga diri merupakan salah satu aspek penting dalam psikologis. Harga diri seseorang dapat mengalami penurunan akibat evaluasi negatif terhadap diri sendiri dan kemampuan diri. Perasaan tidak berharga, tidak berarti, dan rendah diri yang berkepanjangan akibat evaluasi negatif inilah yang disebut dengan harga diri rendah (Sutejo, 2017:77).

Menurut Nurdin (2011:62) harga diri (self-respect) adalah penilaian individu terhadap diri sendiri bertolak dari persepsinya terhadap penilaian lingkungan eksternal pada dirinya. Harga diri bersifat ekstrinsik, yang dibedakan 
sebagai harga diri yang rendah (low self-respect), tinggi (high selfrespect), dan berlebihan (excessive self-respect). Menurut Syam'ani (2011), lansia yang mengalami harga diri rendah memiliki perasaan malu, kurang percaya diri, minder, tidak berguna, rendah diri, tidak mampu, tidak sempurna, menyalahkan diri, menarik diri dan keinginan yang tidak tercapai, seperti keinginan untuk kembali berkumpul dengan teman-teman dan keinginan untuk dapat melakukan aktivitas yang sebelumnya dapat dilakukan.

Menurut Muhith (2015) faktor yang mempengaruhi harga diri salah satunya adalah gangguan fisik dan system keluarga yang tidak berfungsi. Keluhan fisik yang sering dialami lansia adalah sakit kepala, nyeri punggung, gangguan perut dan pencernaan, keluhan seksual dan napas pendek. Secara umum perubahan fisik pada masa lansia yaitu menurunnya fungsi panca indra, minat dan fungsi organ seksual dan kemampuan motorik. Perubahan-perubahan di usia lanjut sering menyebabkan mereka mengalami konflik dengan sesama lansia, anak sendiri, sanak saudara, suami istri, agama dan pribadi (Pieter \& Lubis, 2017:92).

Dampak gangguan fungsi fisik akan memperburuk penyakitpenyakit kronis yang sudah ada sebelumnya. Berbagai penyakit kronis yang dapat diperberat oleh adanya faktor stres antara lain kencing manis, sakit jantung, strok, hipertensi, dan lain sebagainya (Maryam, 2010).

Sistem keluarga dalam meningkatkan harga diri adalah menjalin hubungan saling percaya, memberi kegiatan sesuai kemampuan klien, meningkatkan kontak dengan orang lain, menggali kekuatan klien, dorong mengungkapkan pikiran dan perasaannya, bantu melihat prestasi dan kemapuan klien, bantu mengenal harapan, mengevaluasi diri, membantu klien mengungkapkan upaya yang bisa digunakan dalam menghadapi masalah, menetapkan tujuan yang nyata, mantu klien mengungkapkan beberapa rencana menyelesaikan masalah, membantu memilih cara yang sesuai untuk klien, membantu klien untuk mengubah perilaku negatif dan mempertahankan perilaku positif, sikap keluarga, empati, mengontrol klien, memberi pujian pada klien (Yosep, 2016:265).

Berdasarkan survey awal yang dilakukan pada April 2019 terhadap 10 lansia di Puskesmas Putri Ayu Kota Jambi, 5 lansia mengatakan merasa malu terhadap diri sendiri, merasa takut sesuatu terjadi pada dirinya, tidak dapat hidup mandiri ketika keluarga sedang bepergian, 3 lansia mengatakan tidak merasa takut saat terjadi sesuatu pada dirinya, dapat menyesuaikan diri dengan lingkungan sekitar, merasa dibutuhkan dalam keluarga, 2 lansia mengatakan pandangan diri sendiri lebih baik dengan orang lain dan menerima diri anda apa adanya.

Empat dari 10 lansia mengatakan keluarga mau merawat dan mendengarkan keluhan-keluhan yang dirasakannya dan keluarga memberikan perhatian terhadap perubahan fisik yang saya alami, 3 lansia mengatakan keluarga tidak pernah memberikan informasi tentang kesehatan yang saya alami dan keluarga menyarankan saya 
untuk rutin mengikuti kegiatan kesehatan di Puskesmas atau Posyandu lansia, 3 lansia mengatakan keluarga menemani saya ke fasilitas kesehatan, keluarga menghargai pendapat saya dan keluarga menerima saya apa adanya dengan segala keterbatasan.

Tiga lansia mengatakan susah bergerak dan jika beraktifitas mudah lelah dan mengalami nyeri punggung, 5 lansia mengatakan pengelihatan mulai tidak jelas dan sering salah orang dan sering mengalami sakit perut, 2 lansia mengatakan merasa biasa saja masih bisa beraktifitas meskipun tidak seperti dulu lagi karena kondisi umur. Berdasarkan observasi terlihat 4 lansia yang lebih banyak menunduk dan kontak mata kurang, 3 lansia terlihat memperhatikan saat diberi pertanyaan, dan 3 lansia lainnya terlihat malu-malu saat ditanya dan bicaranya lambat.

\section{METODE PENELITIAN}

Penelitian ini merupakan penelitian cross sectional yang bertujuan untuk mengetahui hubungan gangguan fungsi fisik dan dukungan keluarga dengan harga diri lansia di Puskesmas Putri Ayu Kota Jambi tahun 2019. Populasi dalam penelitian ini yaitu seluruh lansia yang berkunjung di Puskesmas Putri Ayu Kota Jambi tahun 2018 sebanyak 5655 orang, sampel dalam penelitian ini adalah 95 responden. Teknik pengambilan sampel dalam penelitian ini dengan accidental sampling. Pengumpulan data dalam penelitian ini dilakukan melalui pengisian kuesioner. Penelitian ini dilakukan pada tanggal 16 - 29 Mei 2019. Peneliti menggunakan analisa univariat dan bivariat dengan uji statistik chi-square.

\section{HASIL DAN PEMABAHASAN}

a. Gambaran dukungan keluarga pada lansia di Puskesmas Putri Ayu Jambi tahun 2019

Hasil penelitian menunjukan bahwa $65,3 \%$ dukungan keluarga pada lansia baik dan 34,7\% dukungan keluarga pada lansia kurang baik. Hasil menunjukan bahwa dukungan informasional lansia lebih banyak mengatakan keluarga selalu menjelaskan mengenai penyakit yang biasa diderita oleh lansia.

\section{Tabel 1 Distribusi Frekuensi Responden Dukungan Keluarga pada lansia di Puskesmas Putri Ayu Jambi tahun 2019}

\begin{tabular}{|c|c|c|}
\hline No & Dukungan Keluarga & (org) \\
\hline 1 & Kurang Baik & 34,7 \\
\hline \multirow[t]{2}{*}{2} & Baik & 65,3 \\
\hline & Jumlah & 100 \\
\hline \multicolumn{2}{|c|}{ Dukungan penilaian lansia lebih } & lebih banyak mengatakan keluarga \\
\hline \multirow{5}{*}{\multicolumn{2}{|c|}{$\begin{array}{l}\text { banyak mengatakan keluarga } \\
\text { mendukung untuk beraktivitas di luar } \\
\text { rumah. Dukungan instrumental lansia } \\
\text { lebih banyak mengatakan keluarga } \\
\text { mendukung untuk menciptakan suatu }\end{array}$}} & \multirow{6}{*}{$\begin{array}{l}\text { menyemangati agar tetap sehat. } \\
\text { Hasil penelitian menunjukan } \\
\text { bahwa dukungan informasional } \\
\text { lansia lebih banyak mengatakan } \\
\text { keluarga selalu } \\
\text { mengenai penyakit yang biasa } \\
\text { diderita oleh lansia }(71.6 \%)\end{array}$} \\
\hline & & \\
\hline & & \\
\hline & & \\
\hline & & \\
\hline $\begin{array}{l}\text { karya } \\
\text { tangan }\end{array}$ & $\begin{array}{l}\text { erti membuat kerajinan } \\
\text { kungan emosional lansia }\end{array}$ & \\
\hline
\end{tabular}


sedangkan yang menjawab kadangkadang adalah keluarga mengingatkan tentang perubahanperubahan fisik bagi lansia $(13,7 \%)$.

Keluarga berfungsi sebagai sebuah kolektor dan diseminator (penyebar) informasi tentang dunia. Menjelaskan tentang pemberian saran, sugesti, informasi yang dapat digunakan mengungkapkan suatu masalah. Manfaat dari dukungan ini adalah dapat menekan munculnya suatu stressor karena informasi yang diberikan dapat menyumbangkan aksi sugesti yang khusus pada individu. Aspek-aspek dalam dukungan ini adalah nasehat, usulan, saran, petunjuk dan pemberian informasi. Dukungan keluarga mempunyai fungsi informasional yang dapat memberikan naseat, usulan, saran, petunjuk dan memberikan informasi (Setiadi, 2010 :22).

Hasil penelitian ini sejalan dengan penelitian yang dilakukan oleh Susilowati dan Sari (2014) dukungan keluarga dalam meningkatkan harga diri lansia di Dusun Margorejo Desa Manggis Kecamatan Ngancar. Hasil penelitian tentang dukungan informasional termasuk kategori kurang yaitu 21 responden $(58,3)$ yang memberikan dukungan keluarga kurang pada lansia.

Hasil penelitian menunjukan bahwa dukungan penilaian lansia lebih banyak mengatakan keluarga mendukung untuk beraktivitas di luar rumah (40\%), sedangkan yang menjawab kadang-kadang adalah keluarga memberi pujian setiap apa yang telah dilakukan $(28,4 \%)$. Keluarga bertindak sebagai sebuah bimbingan umpan balik, membimbing dan menengahi pemecahan masalah, sebagai sumber dan validator indentitas anggota keluarga diantaranya memberikan support, penghargaan, dan perhatian (Setiadi, $2010: 22$ ).

Hasil penelitian menunjukan bahwa dukungan instrumental lansia lebih banyak mengatakan keluarga mendukung untuk menciptakan suatu karya seperti membuat kerajinan tangan $(66,3 \%)$, sedangkan yang menjawab kadang-kadang adalah keluarga menyiapkan apa yang anda butuhkan (15,8\%). Keluarga merupakan sebuah sumber pertolongan praktis dan konkrit, diantaranya: kesehatan penderita dalam hal kebutuhan makan dan minum, istirahat, terhindarnya penderita dari kelelahan. Keluarga mempunyai fungi ekonomi yaitu untuk memenuhi kebutuhan sandang, pangan dan papan melalui bekerja (Setiadi, 2010:22).

Hasil penelitian menunjukan bahwa dukungan emosional lansia lebih banyak mengatakan keluarga menyemangati agar tetap sehat $(47,4 \%)$, sedangkan yang menjawab kadang-kadang adalah keluarga turut merasakan kesedihan melihat kondisi kesehatan lansia $(21,1 \%)$. Keluarga sebagai tempat yang aman dan damai untuk istirahat dan pemulihan serta membantu penguasaan terhadap emosi. Aspek-aspek dari dukungan emosional meliputi dukungan yang diwujudkan dalam bentuk afeksi, adanya kepercayaan, perhatian, mendengarkan dan didengarkan.

Hasil penelitian didukung oleh penelitian Suryenti (2017) bahwa dari segi dukungan emosional menunjukkan bahwa responden lebih banyak yang menyatakan 
bahwa keluarga jarang turut merasakan apa yang dirasakan anggota keluarga dan jarang membantu anggota keluarga dengan ikhlas.

Untuk itu diharapkan agar dapat meningkatkan dukungan pada pasien lansia dengan cara melakukan penyuluhan secara individu kepada keluarga.

b. Gambaran gangguan fungsi fisik pada lansia di Puskesmas Putri Ayu Jambi tahun 2019

Hasil penelitian menunjukan bahwa $67,4 \%$ gangguan fungsi fisik yang di alami lansia yaiitu gangguan fisik ringan dan $32,6 \%$ gangguan fisik yang di alami lansia yaitu gangguan fisik sedang. Hasil penelitian menunjukan bahwa lansia yang mempunyai gangguan fisik sedang terbanyak kekurangan cairan seperti mengendur atau terlihat tipis $(84,2 \%)$, merasa sulit berjalan karena kaki sakit $(83,2 \%)$ dan mengalami kesulitan membaca (71,6\%). Sedangkan lansia yang merasa mempunyai gangguan fisik ringan dikarenakanblansia merasa tidak mengalami gangguan seperti mudah terluka dan susah untuk sembuh $(89,5 \%)$ dan lansia tidak merasa mengalami gangguan pendengaran $(83,2 \%)$. Bedasarkan distribusi gangguan fungsi fisik lansia dapat dilhat tabel berikut ini:

Tabel 2 Distribusi Frekuensi Responden Gangguan Fungsi Fisik pada lansia di Puskesmas Putri Ayu Jambi tahun 2019

\begin{tabular}{cccc}
\hline No & Gangguan Fungsi Fisik & n (orang) & $\%$ \\
\hline 1 & Mengalami gangguan fisik sedang & 31 & 32,6 \\
2 & Mengalami gangguan fisik ringan & 64 & 67,4 \\
\hline & Jumlah & 95 & 100 \\
\hline
\end{tabular}

Gangguan fungsi fisik diartikan sebagai seseorang yang fisik mengalami masalah sehingga menimbulkan kelainan didalam berinteraksi dengan lingkungan sosialnya. Lansia sering timbul depresi secara diam-diam, yaitu yang menonjol hanya gangguan fisik saja seperti sakit kepala, jantung berdebar-debar, nyeri pinggang, gangguan pencernaan dan lain-lain. Semakin bertambahnya umur manusia, terjadi proses penuaan secara degeneratif yang akan berdampak pada perubahanperubahan pada diri manusia, tidak hanya perubahan fisik, tetapi juga kognitif, perasaan, sosial dan sexual (Maryam, 2010). bahwa lansia lebih banyak mengalami gangguan fungsi fisik yang ringan, namun lansia lebih banyak yang mengalami kekurangan cairan seperti mengendur atau terlihat tipis, merasa sulit berjalan karena kaki sakit dan mengalami kesulitan membaca. Untuk itu diharapkan agar keluarga tetap memberikan dukungan kepada lansia agar lansia dapat termotivasi untuk melakukan pencegahan penyakit yang kronis dengan meningkatkan kesehatan.

c. Gambaran harga diri pada lansia di Puskesmas Putri Ayu Jambi tahun 2019 
Hasil penelitian menunjukan bahwa $38,9 \%$ lansia mempunyai harga diri rendah, 36,8\% lansia mempunyai harga diri tinggi dan $24,2 \%$ lansia mempunyai harga diri normal.

Hasil analisis tabel di atas menunjukan bahwa lansia yang merasa mempunyai harga diri tinggi dikarenakan responden lebih banyak menjawab sangat setuju bahwa dirinya cukup berharga, setidaktidaknya sama dengan orang lain $(34,7 \%)$, merasa bahwa dirinya mampu mengerjakan sesuatu seperti apa yang dapat dilakukan orang lain $(58,9 \%)$. Sedangkan lansia yang merasa mempunyai harga diri rendah dikarenakan masih ada responden yang menjawab netral secara

\begin{tabular}{cccc}
\hline No Harga Diri & \multicolumn{1}{c}{$\begin{array}{c}\mathrm{N} \\
\text { (orang) }\end{array}$} \\
\hline 1 Harga diri rendah & 37 & 38,9 \\
$2 \quad$ Harga diri normal & 23 & 24,2 \\
$3 \quad$ Hrga diri tinggi & 35 & 36,8 \\
\hline Jumlah & 95 & 100 \\
\hline Menurut Syam'ani (2011), & pertolongan jika ada masalah \\
lansia yang mengalami harga diri & terutama kesehatan. \\
rendah memiliki perasaan malu, & d. Hubungan gangguan fungsi fisik \\
kurang percaya diri, minder, tidak \\
berguna, rendah diri, tidak mampu,
\end{tabular}

keseluruhan, puas dengan diri sendiri $(17,9 \%)$ dan merasa bahwa dirinya baik $(16,8 \%)$. Bedasarkan distribusi gambaran harga diri lansia dapat dilihat table 3. Menurut Nurdin (2011:62) harga diri (self-respect) adalah penilaian individu terhadap diri sendiri bertolak dari persepsinya terhadap penilaian lingkungan eksternal pada dirinya. Harga diri bersifat ekstrinsik, yang dibedakan sebagai harga diri yang rendah (low self-respect), tinggi (high selfrespect), dan berlebihan (excessive self-respect). Harga Diri pada lansia di Puskesmas Putri Ayu Jambi tahun 2019
Tabel 3 Distribusi Frekuensi yaitu keluarga sebagai tempat bercerita dan tempat mencari 
Tabel 4 Hubungan

Gangguan Fungsi Fisik dengan

Harga Diri Lansia di Puskesmas Putri Ayu Jambi tahun 2019

\begin{tabular}{|c|c|c|c|c|c|c|c|c|c|c|}
\hline \multirow{3}{*}{ No } & \multirow{3}{*}{ Gangguan Fungsi Fisik } & \multicolumn{6}{|c|}{ Penghargaan Diri } & \multirow{2}{*}{\multicolumn{2}{|c|}{ Jumlah }} & \multirow{3}{*}{$\begin{array}{c}p- \\
\text { value }\end{array}$} \\
\hline & & \multicolumn{2}{|c|}{ Rendah } & \multicolumn{2}{|c|}{ Normal } & \multicolumn{2}{|c|}{ Tinggi } & & & \\
\hline & & $\mathrm{n}$ & $\%$ & $\mathrm{n}$ & $\%$ & $\mathrm{n}$ & $\%$ & $\mathrm{n}$ & $\%$ & \\
\hline 1. & $\begin{array}{l}\text { Mengalami gangguan } \\
\text { fungsi fisik sedang }\end{array}$ & 25 & 80,6 & 4 & 12,9 & 2 & 6,5 & 31 & 100 & 0.000 \\
\hline 2. & $\begin{array}{l}\text { Mengalami gangguan } \\
\text { fungsi fisik ringan }\end{array}$ & 12 & 18,8 & 19 & 29,7 & 33 & 51,6 & 64 & 100 & \\
\hline & Jumlah & 37 & 38,9 & 23 & 24,2 & 35 & 36,8 & 95 & 100 & \\
\hline
\end{tabular}

Hasil uji statistik diperoleh nilai p-value 0,000. Hasil ini menunjukkan bahwa ada hubungan yang bermakna antara gangguan fungsi fisik dengan harga diri lansia di Puskesmas Putri Ayu Jambi tahun 2019.

Hasil penelitian menunjukkan bahwa responden yang mengalami gangguan fungsi fisik sedang lebih banyak yang mempunyai harga diri rendah $(80,6 \%)$ dan sebaliknya responden yang mengalami gangguan fungsi fisik ringan yang baik lebih banyak yang mempunyai harga diri sedang $(51,6 \%)$. Namun masih ada responden yang mempunyai mengalami gangguan fisik ringan tetapi harga diri rendah, hal ini dikarenkan responden tersebut kurang mendapatkan informasi mengenai kesehatan serta dipengaruhi oleh faktor yang lain seperti dukungan keluarga. Keadaan tersebut memperlihatkan bahwa gangguan fungsi fisik memegang peranan yang penting bagi responden harga diri lansia, hal itu adalah sesuatu yang wajar karena mereka yang kesehatannya baik akan dapat mengerti cara melakukan menjaga kesehatan.

Hasil penelitian ini sejalan dengan penelitian yang dilakukan oleh Nugroho (2017) perubahan fungsi fisik dan dukungan keluarga dengan respon psikososiat pada lansia di Keturahan Kembangarum Semarang. Hasil menunjukkan bahwa hubungan antara Perubahan fungsi fisik dengan respon psikososial Lansia diperoleh $\mathrm{p}$ value $=0,000 \quad(\mathrm{p}<0,05)$ yang berarti adanya hubungan yang signifikan antara perubahan fungsi fisik dan denga respon psikososial lansia.

Gangguan fungsi fisik diartikan sebagai seseorang yang fisik mengalami masalah sehingga menimbulkan kelainan didalam berinteraksi dengan lingkungan sosialnya. Lansia sering timbul depresi secara diam-diam, yaitu yang menonjol hanya gangguan fisik saja seperti sakit kepala, jantung berdebar-debar, nyeri pinggang, gangguan pencernaan dan lain-lain. Semakin bertambahnya umur manusia, terjadi proses penuaan secara degeneratif yang akan berdampak pada perubahanperubahan pada diri manusia, tidak hanya perubahan fisik, tetapi juga kognitif, perasaan, sosial dan sexual (Maryam, 2010).

Hasil penelitian menunjukkan bahwa ada hubungan gangguan fungsi fisik dengan harga diri lansia. Lansia lebih banyak mengalami gangguan fungsi fisik kekurangan cairan seperti mengendur atau terlihat tipis, sulit berjalan karena 
kaki sakit dan mengalami kesulitan membaca. Sedangkan untuk harga diri lansia lebih banyak yang merasa kurang puas dengan diri sendiri. Untuk itu diharapkan agar petugas kesehatan dapat memberikan penyuluhan langsung kepada lansia mengenai gangguan fungsi fisik yang umum dialami oleh lansia sehingga lansia dapat menerima perubahanperubahan yang terjadi pada dirinya.

e. Hubungan dukungan keluarga dengan harga diri lansia di Puskesmas Putri Ayu Jambi tahun 2019

Berdasarkan hasil penelitian didapatkan dari 33 responden yang memiliki dukungan keluarga yang kurang baik, sebagian besar 20 responden $(60,6 \%)$ mempunyai harga diri rendah dan dari 62 responden yang memiliki dukungan keluarga yang baik, sebagian besar 27 responden $(43,5 \%)$ mempunyai harga

\section{Tabel 5 \\ Hubungan \\ Dukungan Keluarga}

\begin{tabular}{|c|c|c|c|c|c|c|c|c|c|c|}
\hline \multirow{3}{*}{ No } & \multirow{3}{*}{$\begin{array}{c}\text { Dukungan } \\
\text { Keluarga }\end{array}$} & \multicolumn{6}{|c|}{ Penghargaan diri } & \multirow{2}{*}{\multicolumn{2}{|c|}{ Jumlah }} & \multirow{2}{*}{$\begin{array}{c}p- \\
\text { value }\end{array}$} \\
\hline & & \multicolumn{2}{|c|}{ Rendah } & \multicolumn{2}{|c|}{ Normal } & \multicolumn{2}{|c|}{ Tinggi } & & & \\
\hline & & $\mathrm{n}$ & $\%$ & $\mathrm{n}$ & $\%$ & $\mathrm{n}$ & $\%$ & $\mathrm{n}$ & $\%$ & \multirow{4}{*}{0,007} \\
\hline 1. & Kurang Baik & 20 & 60,6 & 5 & 15,2 & 8 & 24,2 & 33 & 100 & \\
\hline 2. & Baik & 17 & 27,4 & 18 & 29,0 & 27 & 43,5 & 62 & 100 & \\
\hline & Jumlah & 37 & 38,9 & 23 & 24,2 & 35 & 36,8 & 95 & 100 & \\
\hline
\end{tabular}

Hasil penelitian Perdana (2018)

hubungan antara dukungan keluarga dengan harga diri pada pensiunan TNI. Hasil analisis data mendapati hasil koefisien korelasi $(\mathrm{rxy})=0,81$ dan signifikansi $(\mathrm{p})=0,000 ; \mathrm{p}<$ 0,01 . Sumbangan efektif dukungan keluarga terhadap harga diri sebesar $66 \%$. Sesuai dengan teori dukungan keluarga pada lansia adalah sikap, tindakan dan penerimaan keluarga terhadap anggotanya. Anggota diri tinggi. Hasil uji statistik diperoleh nilai $\mathrm{p}$-value 0,007 . Hasil ini menunjukkan bahwa ada hubungan yang bermakna antara dukungan keluarga dengan harga diri lansia di Puskesmas Putri Ayu Jambi tahun 2019. Hasil penelitian menunjukkan bahwa responden yang memiliki dukungan keluarga yang kurang baik lebih banyak yang mempunyai harga diri rendah $(60,6 \%)$ dan sebaliknya responden yang memiliki dukungan keluarga yang baik lebih banyak yang mempunyai harga diri tinggi (43,5\%). Keadaan tersebut memperlihatkan bahwa dukungan keluarga memegang peranan yang penting bagi responden terhadap harga diri lansia, hal itu adalah sesuatu yang wajar karena mereka yang lebih baik dukungan keluarganya akan termotivasi dan mempunyai keinginan untuk meningkatkan harga dirinya.

Harga Diri Lansia di Puskesmas Putri Ayu Jambi tahun 2019 
mengemukakan bahwa lansia akan merasa lebih aman apabila hidup ditengah-tengah keluarga yang penuh dengan dukungan emosional. Keluarga mempunyai fungsi psikologis yaitu memberikan kasih sayang dan rasa aman, memberikan perhatian di antara anggota keluarga, membina pendewasaan kepribadian anggota keluarga, memberikan identitas keluarga.

Dampak dari kurangnya dukungan dari keluarga dapat mengakibatkan, lansia merasa tidak nyaman dan tidak dapat menerima diri dengan perubahan-perubahan yang terjadi. Lansia menjadi tidak percaya diri, cenderung untuk menyalahkan diri, memiliki harga diri yang rendah, lansia merasa tidak berguna, tidak berdaya, putus asa, kekecewaan, rasa kesal, bersalah dan dapat mengakibatkan Depresi pada lansia yang dipengaruhi oleh berbagai faktor seperti suasana hati, kondisi kesehatan, kehilangan sesuatu yang sangat dicintai, kehilangan pekerjaan. Dengan adanya bantuan dan dukungan dari keluarga, Maka sebagian masalah mental (harga diri rendah) dan emosional dapat dicegah (Maramis dalam Azizah, 2011).

Hasil penelitian menunjukkan bahwa masih ada responden yang kurang puas dengan diri sendiri dan merasa bahwa dirinya kurang baik. Untuk itu diharapkan agar keluarga dapat memberikan kasih sayang dan rasa aman, memberikan perhatian di antara anggota keluarga. Diharapkan keluarga mengingatkan tentang perubahan-perubahan fisik bagi lansia, memberi pujian setiap apa yang telah dilakukan, menyiapkan apa yang anda butuhkan dan turut merasakan kesedihan melihat kondisi kesehatan lansia. Keluarga tetap memberikan dukungan kepada lansia agar lansia dapat termotivasi untuk meningkatkan kesehatan.

\section{SIMPULAN}

1. Sebanyak $38,9 \%$ lansia mempunyai harga diri rendah, $36,8 \%$ lansia mempunyai harga diri tinggi dan 24,2\% lansia mempunyai harga diri normal

2. Sebanyak 65,3\% dukungan keluarga pada lansia baik dan $34,7 \%$ dukungan keluarga pada lansia kurang baik

3. Sebanyak $67,4 \%$ gangguan fungsi fisik yang di alami lansia yaiitu gangguan fisik ringan dan $32,6 \%$ gangguan fisik yang di alami lansia yaitu gangguan fisik sedang

4. Ada hubungan yang bermakna antara gangguan fungsi fisik dengan harga diri lansia di Puskesmas Putri Ayu Jambi tahun 2019 dengan nilai $p$-value 0,000

5. Ada hubungan yang bermakna antara dukungan keluarga dengan harga diri lansia di Puskesmas Putri Ayu Jambi tahun 2019 dengan nilai $p$-value 0,007

\section{SARAN}

1. Bagi Puskesmas Putri Ayu Jambi

Dengan penelitian ini diharapkan agar petugas kesehatan di Puskesmas meningkatkan penyuluhan tentang kesehatan lansia dan harga diri lansia melalui penyuluhan khususnya tentang perubahan-perubahan fisik bagi lansia, pujian untuk lansia, 
kebutuhan lansia dan kondisi kesehatan lansia

2. Bagi Ilmu Keperawatan

Dengan penelitian ini diharapkan agar dapat mengembangkan ilmu keperawatan mengenai kesehatan lansia dan harga diri lansia melalui pendidikan kesehatan tentang kebutuhan pola asuh lansia

3. Keluarga dan Lansia

Diharapkan keluarga dapat meningkatkan peran sertanya dalam upaya peningkatan kesehatan fungsi fisik lansia dan dapat menangani harga diri lansia melalui dukungan dan motivasi yang diberika kepada lansia tentang gangguan fungsi fisik lansia. Diharapkan keluarga mengingatkan tentang perubahan-perubahan fisik bagi lansia, memberi pujian setiap apa yang telah dilakukan, menyiapkan apa yang anda butuhkan dan turut merasakan kesedihan melihat kondisi kesehatan lansia

4. Bagi Penelitian Selanjutnya

Disarankan bagi peneliti lain agar melakukan penelitian lebih lanjut dengan memperhatikan variabel-variabel lain yang dapat mempengaruhi harga diri lansia yang belum diteliti seperti perubahan-perubahan fisik bagi lansia, pujian untuk lansia, kebutuhan lansia dan kondisi kesehatan lansia

\section{DAFTAR PUSTAKA}

1. Darmayanti, E.S., \& Purnamasari, A.(2011). Berpikir positif dengan harga diri wanita yang mengalami masa premenopause. Jurnal Universitas Ahmad Dahlan, Yogyakarta, Humanitas, Vol.VIII No. 2

2. Dinkes Kota Jambi, 2018. Pencatatan dan Pelaporan Kesehatan Lansia Dinas Kesehatan Kota Jambi Tahun 2017. Jambi

3. Dinkes Provinsi Jambi, 2016. Profil Dinas Kesehatan Provinsi Jambi. Jambi

4. Direja. (2011). Asuhan Keperawatan Jiwa. Yogyakarta: Nuha. Medika.

5. Friedman, M. (2010). Buku Ajar Keperawatan Keluarga : Riset, Teori, dan Praktek. Edisi ke-5. Jakarta: EGC

6. Maryam, S. (2010). Menengenal Usia Lanjut dan Perawatannya. Jakarta: Salemba Medika

7. Muhith, A. (2015). Pendidikan Keperawatan Jiwa (Teori dan Aplikasi). Yogyakarta: Andi.

8. Nugroho (2014).

Keperawatan Gerontik dan Geriatrik. Jakarta : EGC

9. Nugroho (2017) Perubahan Fungsi Fisik Dan Dukungan Keluarga Dengan Respon Psikososiat Pada Lansia di Keturahan Kembangarum Semarang. Fikkes. Jurnal Keperawatan. Vol. 1 No. 1 Oktober 2017. 45 - 57

10. Nurdin, (2011). Tumbuh Kembang Perilaku Manusia. 
Jakarta: Penerbit Buku Kedokteran EGC

11. Perdana (2018) Hubungan Antara Dukungan Keluarga Dengan Harga Diri Pada Pensiunan TNI. Program studi psikologi. Fakultas psikologi. Universitas Muhammadiyah Surakarta

12. Pieter \& Lubis. (2011). Pengantar Psikologi dalam Keperawatan. Jakarta: Kencana Prenada Group

13. Setiadi. (2010). Konsep Dan Proses Keperawatan Keluarga. Yogyakarta: Graha 14. Suryenti,V (2017) Dukungan dan Beban Keluarga dengan Kemampuan Keluarga Merawat Pasien Resiko Perilaku Kekerasan di Klinik Jiwa Rumah Sakit Jiwa Provinsi Jambi. Jurnal Psikologi Jambi. p-ISSN : 2528-2735. Volume 2, NO 2, Oktober 2017 e-ISSN : 2580-7021

15. Susilowati dan Sari (2014) Dukungan Keluarga Dalam Meningkatkan Harga Diri Lansia di Dusun Margorejo Desa Manggis Kecamatan Ngancar. Jurnal AKP. Vol. 5 No. 2, 1 Juli - 31 Desember 2014

16. Sutejo. 2017. Keperawatan Jiwa. Yogyakarta : Pustaka Baru Press

17. Syam'ani. (2011). Studi Fenomenologi Tentang
Pengalaman Menghadapi Perubahan Konsep Diri : Harga Diri Rendah Pada Lansia di Kecamatan Jekan Raya Kota Palangka Raya. Jurnal Keperawatan Jiwa . Volume 1, No. 1, Mei 2013; 6069

18. Yosep (2016). Keperawatan Jiwa. Bandung : Refia Aditama 